\title{
Sosialisasi Reduce, Reuse, Recycle (3R) Berbasis Lingkungan Masyarakat Desa Jelegong, Kutawaringin, Bandung Dengan Memanfaatkan Media Internet
}

\author{
Samsinar $^{1}$, Wiwin Windihastuty ${ }^{2}$ \\ Fakultas Teknologi Informasi, Universitas Budi Luhur \\ $\underline{\text { samsinar@budiluhur.ac.id }}^{1)}$, wiwin.windihastuty@ budiluhur.ac.id ${ }^{2)}$
}

\begin{abstract}
Abstrak: Permasalahan limbah rumah tangga menjadi permasalahan yang harus dikelola dengan baik. Manajemen limbah domestik yang terkendali dengan baik merupakan suatu pendekatan untuk menanggulangi limbah domestik secara efisien. Pengabdian kepada Masyarakat adalah proses pengabdian dosen melalui berbagai kegiatan langsung di masyarakat. Dosen juga menjadi bagian dari masyarakat secara aktif dan kreatif terlibat dalam dinamika yang terjadi di masyarakat. Dosen mempunyai peran strategis sebagai agen perubahan pada lingkungan masyarakat, melalui kegiatan pengabdian kepada masyarakat di Desa Jelegong Kutawaringin, Bandung Barat dengan Sosialisasi Reduce, Reuse, Recycle (3R) dan memanfaatkan media internet pada media sosial. Hasilnya masyarakat dapat lebih memahami tentang bahaya limbah rumah tangga yang tidak dikelola dengan baik dan masyarakat juga dapat menggunakan sarana media internet untuk dijadikan wadah dalam pemanfaatkan 3R yang dapat bernilai guna bagi Masyarakat.
\end{abstract}

Kata Kunci: 3R, Sampah Rumah Tangga, Internet.

\section{PENDAHULUAN}

Universitas Budi Luhur merupakan salah satu perguruan tinggi yang ada di Indonesia. Sebagai perguruan tinggi, Universitas Budi Luhur memiliki kewajiban melakukan Tri Dharma Perguruan Tinggi yang mencakup kegiatan Pendidikan, Penelitian, dan Pengabdian kepada Masyarakat. Agar Perguruan Tinggi dapat bersentuhan langsung dengan masyarakat melalui pengamalan ilmu dan teknologi, maka kegiatan pengabdian kepada masyarakat harus dilakukan melalui program-program kemasyarakatan yang relevan. Implementasi Tri Dharma Perguruan Tinggi tersebut dimaksudkan dilakukan oleh dosen yang secara konkret berwujud Pengabdian kepada Masyarakat (PPM). PPM itu sendiri adalah bagian dari penyelenggaraan pendidikan tinggi yang menempatkan dosen di luar kampus agar dapat melakukan kegiatan bersama masyarakat untuk membantu dan mendampingi masyarakat menggali potensi sumber daya manusia (SDM) dan sumber daya alam (SDA) lokal yang ada untuk mengatasi permasalahan masyarakat.

Kegiatan penyelenggaraan PPM dikelola oleh Direktorat Riset dan Pengabdian Masyarakat. PPM adalah suatu kegiatan intrakurikuler yang memadukan pelaksanaan Tri Dharma Perguruan Tinggi untuk memberikan bekal kepada mahasiswa berupa pengalaman belajar dan pemberdayaan masyarakat. PPM merupakan wahana penerapan dan pengembangan ilmu pengetahuan, teknologi dan seni, dilaksanakan di luar kampus, dalam waktu, mekanisme kerja, dan persyaratan tertentu. Oleh karena itu, kegiatan dan pengelolaan PPM tersebut menjamin adanya "keterkaitan" antara dunia akademik yang teoritik dengan 
dunia nyata. Kegiatan PPM ini dengan mengusung tema "Sosialisasi Reduce, Reuse, Recycle (3R) Berbasis Lingkungan Masyarakat dengan Memanfaatkan Media Internet kepada Masyarakat Jelegong, Kutowaringin, Bandung Barat".

Tim PPM UBL akan melakukan kegiatan PPM di Desa Jelegong, Kecamatan Kutawaringin, Bandung Barat. Pemilihan tema tersebut tidak terlepas dari kondisi masyarakat disana. Sasaran kegiatan yaitu masyarakat umum, kegiatan dilaksanakan dengan berbasis pemberdayaan potensi desa dengan Sosialisasi 3R melalui pemanfaatan Media Internet (Kemendag, 2014) salah satunya yaitu; Sosial Media.

3R merupakan solusi yang dapat digunakan dalam menjaga lingkungan agar terhindar dari bahaya limbah domestik yang cukup murah dan mudah untuk di lakukan setiap warga masyarakat dalam kegiatan sehari-hari. (Farida, 2013). Faktor dari semakin banyaknya jumlah penduduk maka konsumsi masyarakat juga semakin meningkat yang berakibat semakin banyaknya jumlah sampah domestik dan menjadi tidak terkontrol dan tidak terkelola dengan baik. (Faizah, 2008)

Dalam program tersebut diharapkan nantinya Desa Jelegong Kecamatan Kutawaringin Bandung Barat ini akan menjadi masyarakat madani yang berorientasi pada kemandirian ekonomi dan peningkatan ilmu pengetahuan (Imana, 2018). Pemanfaatan Media Internet (Kemendag, 2014) yang akan menjadi wadah yang dapat bernilai guna untuk bagi masyarakat dikembali.

Adapun permasalahan yang diperoleh dari masyarakat sasaran dalam kegiatan ini adalah mendorong Masyarakat desa untuk mengurangi limbah dan mengubahnya menjadi lahan hijau dan dari limbah rumah tangga yang ada dapat menghasilkan produk yang bermanfaat. Selain itu menanamkan pola pikir warga sepanjang aliran Sungai Citarum (Greenpeace, 2018) yang memiliki budaya membuang sampah ke sungai dengan memberikan edukasi dan pembelajaran tentang Reduce, Reuse, Recycle (3R) (Tamyuiz, Hamidah, Widiyanti, \& Rahmayanti, 2018) bagi warga sepanjang sungai Citarum khususnya Desa Jelegong kecamatan Kutawaringin agar bermanfaat dan memiliki nilai ekonomis, rekreatif serta edukatif. Pengolahan sampah merupakan kegiatan yang sistematis, menyeluruh, dan terus menerus dalam mengurangi dan penanganan sampah yang di jelaskan dalam UU No 18 Tahun 2008. (DPRRI, 2008) dan juga pengelolaan sampah bertujuan untuk menjaga lingkungan dan kesehatan masyarakat yang kemudian sampah rumah tangga bisa dijadikan sebagai sesuatu yang bernilai. (PP, 2012)

Pelaksanaan Pengabdian Pada Masyarakat (PPM) ini diharapkan menjadi sebuah ajang pendedikasian Instansi terhadap permasalahan-permasalahan yang ada di masyarakat, untuk kemudian dapat diselesaikan bersama. Output dari kegiatan ini juga dapat menjadi sebuah pertimbangan pemerintah dalam mengambil sebuah kebijakan mengenai pemerataan pembangunan manusia.

Pada kesempatan ini Universitas Budi Luhur melalui Pengabdian kepada Masyarakat (PPM) mengangkat 3 tema dalam kegiatannya di Desa Jelegong. Ke 3 (tiga) tema tersebut adalah: Sosialisasi Reduce, Reuse, Recycle (3R) Berbasis Lingkungan Masyarakat dengan Memanfaatkan Media Internet, (Mellyanawaty et al., 2018). Penanaman pohon dan pembuatan biopori ini adalah kegiatan gabungan dengan masyarakat, aparat daerah dan TNI yang bertanggung jawab di Desa Jelegong kecamatan Kutawaringin dan yang terakhir adalah sosialisai mengenai perawatan dan pemeliharaan yang sudah dibangun. (Yanuar, 2018) 
a) Universitas Budi Luhur melalui Pengabdian Masyarakat ikut berperan serta mengembalikan Sungai Citarum kembali menjadi bersih dan hijau dengan penanaman pohon dan pembuatan bipori serta mengenalkan media social internet. (Greenpeace, 2018)

b) Tim Dosen yang tergabung dalam Pengabdian kepada Masyarakat Universitas Budi Luhur dapat mengetahui faktor-faktor yang menghambat dalam merealisasikan Program Citarum Harum.

c) Mengetahui seberapa besar/kecil nya peran serta masyarakat, Pemda dan TNI dalam mendukung kegiatan Citarum Harum.

d) Mengetahui pencapaian yang telah diraih selama melaksanakan kegiatan Citarum Harum.

\section{METODE}

Dalam Pengabdian kepada Masyarakat (PPM) ini metode yang digunakan dalam pelaksanaan kegiatan ini adalah:

\section{a) Observasi/Pengamatan}

Pengumpulan data dilakukan dengan cara mengamati dan mencatat secara sistimatik gejala-gejala yang ada di Desa Jelegong. Pada metode pegamatan ini kami akan melakukan kunjungan ke beberapa lokasi di Desa Jelegong yang mencakup fasilitas Desa, kawasan permukiman, juga kawasan wisata disekitar Desa yang berpotensi besar dalam pengenalan wilayah Desa bagi wisatawan asing maupun lokal yang berpotensi meningkatkan pendapatan Desa dari sektor pariwisata serta teknologi. (Yanuar, 2018)

\section{b) Interview}

Metode ini disebut juga dengan metode wawancara, yaitu suatu metode pengumpulan data yang dilakukan melalui tanya jawab secara langsung dari narasumber. Interview merupakan alat pengumpulan informasi dengan cara mengajukan pertanyaan secara lisan, ciri utama dari interview adalah kontak langsung dengan tatap muka antara pencari informasi dengan sumber informasi. Dalam wawancara secara mendalam ini dilakukan oleh peneliti terhadap informan yang menjadi obyek dari penelitian ini yaitu kepala Desa dan salah satu warga. Wawancara ini bertujuan untuk memperoleh informasi yang ada relevan dengan pokok persoalan penelitian yaitu kerja sama mahasiswa dengan masyarakat desa Jelegong.

\section{c) Dokumentasi}

Dalam Pengabdian kepada Masyarakat ini kami menampilkan kegiatan yang berlangsung berupa dokumen foto-foto dan video. Metode dokumentasi ini bertujuan untuk mengamati objek-objek menarik dari Desa Jelegong, baik dari segi masyarakat, sosial ekonomi dan pariwisata yang ada di Desa Jelegong dan sekitarnya.

Indikator keberhasilan program-program tersebut dapat dilihat dari antusiasme masyarakat dalam partisipanya saat pelaksanaan kegiatan. Dalam pelaksanaannya kami selalu berupaya untuk melibatkan peran serta seluruh lapisan masyarakat yang terdapat di wilayah Desa Jelegong dengan harapan setiap kegiatan yang telah terlaksana dapat direalisasikan dalam kehidupan sehari-hari.

Dalam kegiatan ini perencanaan didahului dengan kegiatan analisis kebutuhan yang diawali dengan survey ke lokasis sasaran, kemudian melakukan wawancara dengan pihak 
terkait dalam hal ini perangkat pemerintahan wilayah, masyarakat sekitar dan TNI yang bertugas di wilayah Desa Jelegong. Dari hasil survey tersebut maka diketahui kebutuhan dan kesempatan bagi pelaksana program kegiatan ini untuk memberikan materi tentang Sosialisasi Reduce, Reuse, Recycle (3R) Berbasis Internet dilingkungan Masyarakat Jelegong, Kutowaringin, Bandung Barat. (Subekti, 2010)

Berdasarkan analisis kebutuhan, hasil observasi dan wawancara maka instrument kegiatan yang harus disiapkan oleh pelaksana adalah materi terkait $3 \mathrm{R}$ dan instrument evaluasi. Target program dan perencanaan yang di susun maka model pelaksanaan program kegiatan untuk penerapan pada PPM, seperti yang terlihat pada Gambar 1 berikut ini:
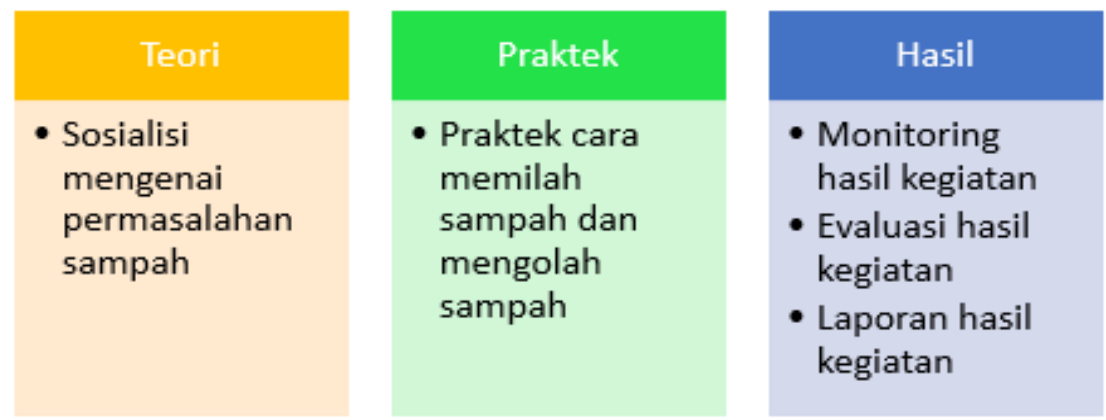

Gambar 1. Metode Penerapan IPTEKS

Dari Gambar 1 terlihat bahwa metode penerapan IPTEKS pada kegiatan ini dimulai dari pemahaman mengenai teori-teori yang dibutuhkan sesuai dengan tujuan program kegiatan, selanjutnya pelaksana akan mengimplementasikan penguasaan teori untuk memecahkan rumusan masalah dan pencapaian tujuan program kegiatan. Tahap akhir adalah evaluasi yang terdiri dari kegiatan konfirmasi hasil luaran program kegiatan dan penuerahan hasil luaran program kegiatan kepada masyarakat sasaran.

Pelaksanaan program kegiatan ini memiliki evaluasi yang dilakukan bersama antara pelaksana program dengan masyarakat sasaran dalam bentuk kuesioner bagi seluruh peserta kegiatan, untuk mengukur apakah pemahaman mereka terhadap kegiatan Reduce, Reuse, Recycle telah dipahami.

\section{HASIL DAN PEMBAHASAN}

Kegiatan Pengabdian kepada Masyarakat (PPM) dilaksanakan yang bertempat pada Area lapangan kegiatan olahraga Desa Jelegong yang dilaksanakan selama 1 hari pada tanggal 31 Oktober 2019. Kegiatan PPM ini dengan memberikan sosialisasi mengenai pemanfaatan limbah sampah rumah tangga yang selalu ada pada masyarakat. Sosialisasi diberikan agar masyarakat sadar akan bahaya nya limbah sampah rumah tangga.

Sebelum melaksanakan kegiatan sosialisasi pada lokasi yang telah disepakati sebelumnya, Tim PPM terlebih dahulu melakukan koordinasi dikantor desa Jelegong untuk memastikan bahwa kegiatan sosialisasi telah siap dilaksanakan, yang terlihat pada gambar 2 . 


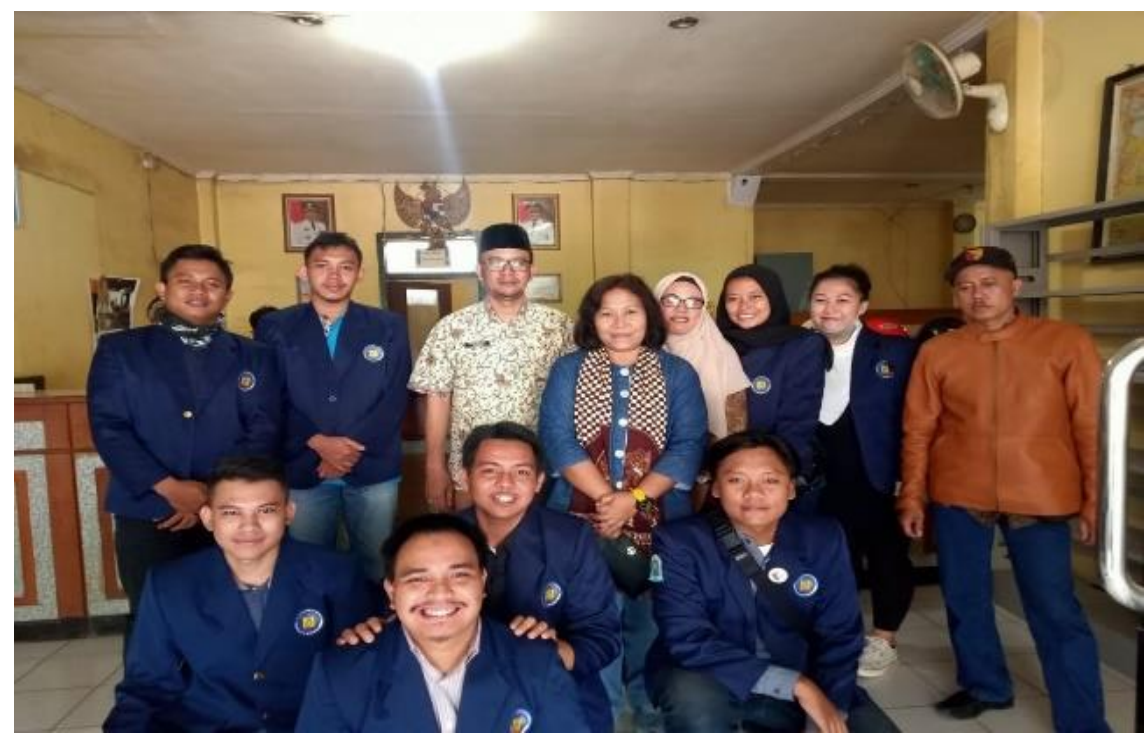

Gambar 2. Koordinasi di Kantor Desa Jelegong

Sebelum sosialisasi yang sampaikan oleh pemateri kepada peserta, acara kegiatan diawali dengan sambutan oleh Kepala Desa Jelegong. Sambutan yang diberikan diungkapkan dengan adanya dukungan penuh atas terlaksana nya acara kegiatan sosialisasi tersebut dan lanjutannya kemudian, yang terlihat pada Gambar 3 berikut.

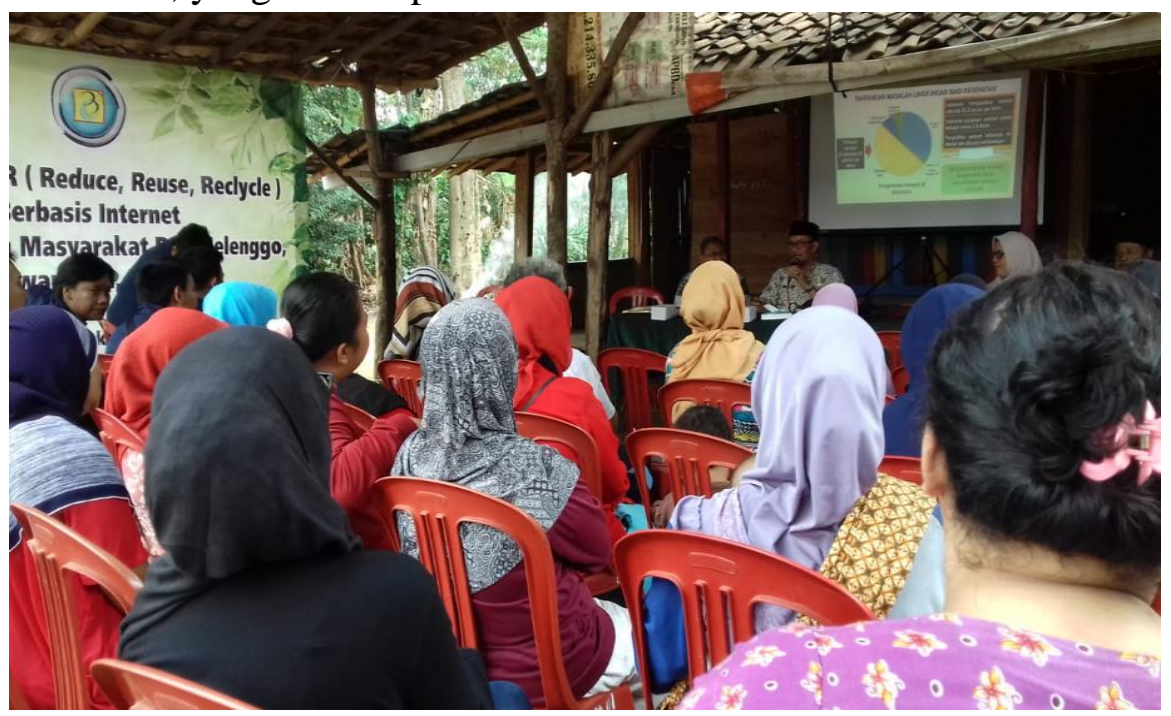

Gambar 3. Sambutan oleh Kepala Desa Jelegong

Sebelum Pemateri menyampaikan materi acara terlebih dahulu Ketua Tim Pelaksana memberikan sambutan berikutnya dan juga mengawali dengan memaparkan materi pembuka mengenai sampah.

Dalam proses pelaksanaannya sosialisasi, seluruh peserta terlihat begitu antusias serta semangat dalam mengikuti acara sosialisi yang diberikan oleh pemateri tentang segala hal mengenai 3R, yang terlihat pada Gambar 4. 


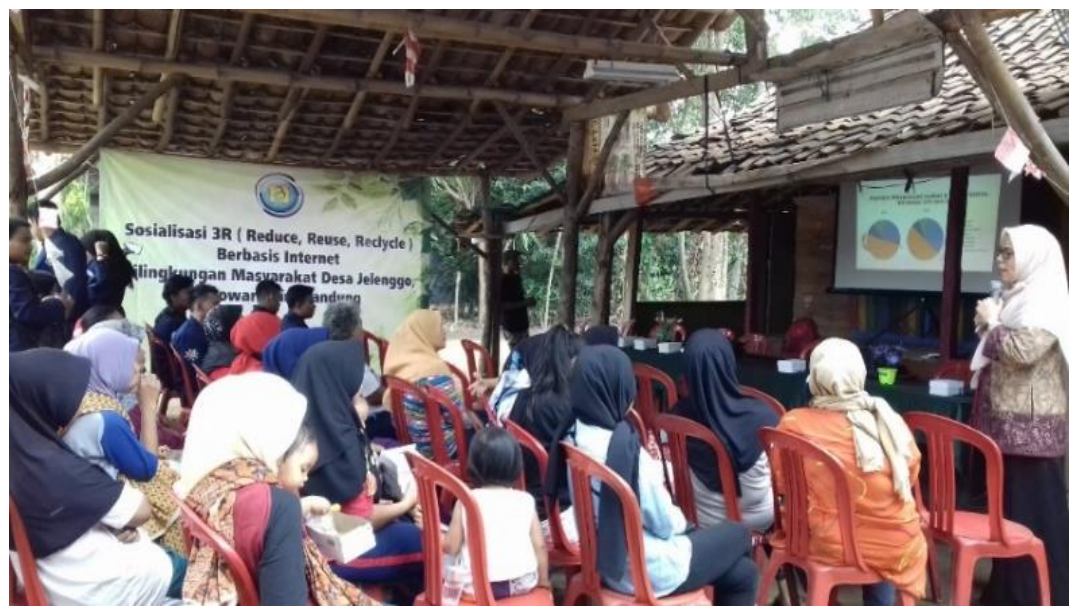

Gambar 4. Pemateri Memberikan Sosialisasi Tentang 3R

Setelah sosialisasi selesai dilakukan, Tim PPM melakukan foto bersama dengan seluruh peserta yang terlihat pada Gambar 5

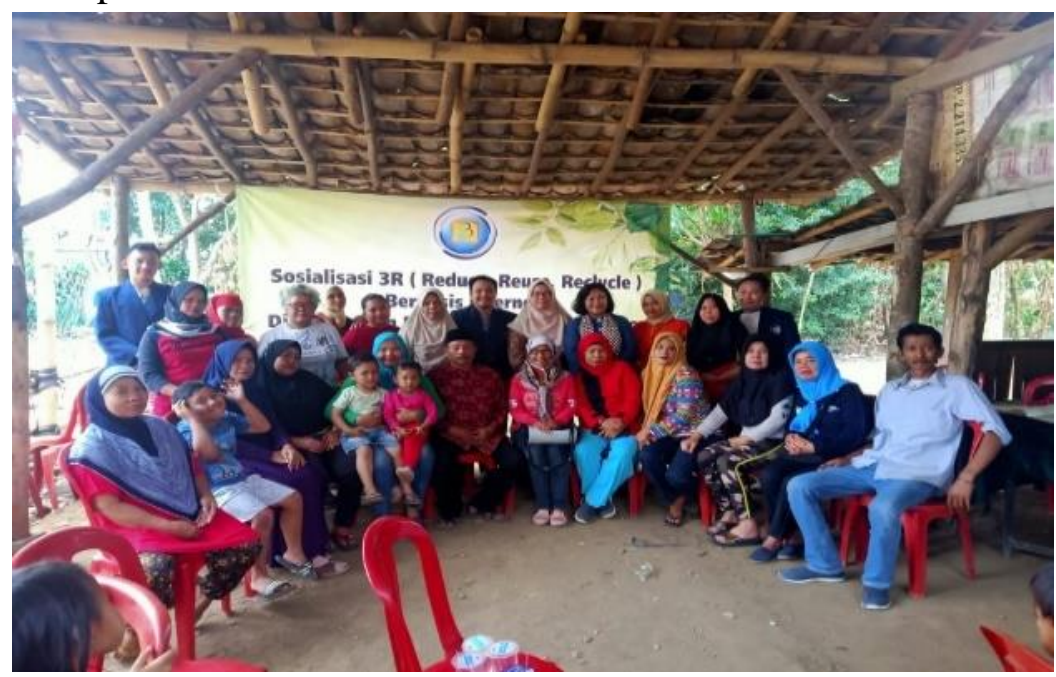

Gambar 5. Foto Bersama Seluruh Peserta Sosialisasi

Hasil yang diperoleh dari sosialisasi ini dapat membuka wawasan dari masing-masing peserta sosialisasi mengenai bahaya limbah sampah rumah tangga; Menggerakkan kesadaran bagi masyarakat Desa agar menjadi lebih peduli mengenai sampah demi kesehatan dan kebersihan lingkungan. Capaian yang dihasilkan yaitu semangat dan antusiasme peserta sosialisasi dalam mengikuti setiap materi yang disampaikan, antusis tersebut terlihat dari banyaknya pertanyaan-pertanyaan yang diajukan kepada tim PPM.

\section{KESIMPULAN DAN SARAN}

\subsection{Kesimpulan}

Berdasarkan uraian hasil pembahasan diatas, maka dapat disimpulkan bahwa proses kegiatan sosialisasi Reduce, Reuse, Recycle (3R) berbasis lingkungan masyarakat Desa Jelegong Kutawaringin, Bandung Barat berjalan dengan sukses serta lancar terbukti antusiasnya seluruh peserta sosialisasi pada saat pelaksanaan acara dan kegiatan Pengabdian Kepada Masyarakan ini. 


\subsection{Saran}

Kegiatan ini tidak boleh hanya berhenti sampai dikegiatan sosialisasi ini saja, akan dilanjutkan pada kegiatan PPM selanjutnya yaitu Implementasi dari kegiatan sosialisasi ini terhadap limbah sampah rumah tangga masyarakat Jelegong agar terwujudnya 3R, yang nantinya dapat bernilai ekonomis yang bernilai guna atau bernilai jual bagi masyarakat desa dengan memanfaatkan media Internet salah satunya Media Sosial.

\section{UCAPAN TERIMA KASIH}

Tim Pelaksanaan kegiatan Pengabdian kepada Masyarakat berterima kasih kepada Direktorat Riset dan Pengabdian Kepada Masyarakat Universitas Budi Luhur yang telah mendanai kegiatan ini, serta Kepala Desa dan Warga Desa Jelegong khususnya dan semua pihak secara langsung maupun tidak langsung yang telah memberikan dukungan nya sehingga kegiatan sosialisasi ini dapat terlaksana dengan baik dan sukses.

\section{DAFTAR PUSTAKA}

DPRRI. Pengelolaan Sampah, No. 18, 1 (2008). Indonesia. Retrieved from https://peraturan.bpk.go.id/Home/Details/39067/uu-no-18-tahun-2008

Faizah. (2008). Pengelolaan Sampah Rumah Tangga Berbasis Masyarakat. Tesis. Universitas Diponegoro.

Farida, A. N. (2013). 3R (Reduce, Reuse, Recycle). Retrieved from https://www.kompasiana.com/annisa.tekkimits/5528c8b6f17e6143088b45a4/3r-reducereuse-recycle\#

Greenpeace. (2018). Citarum Nadiku, Mari Rebut Kembali. Retrieved from http://www.greenpeace.org/seasia/id/campaigns/toxics/Air/citarum

Imana, L. F. (2018). Implementasi Program 3R Dalam Pemberdayaan Masyarakat di Bank Sampah Purwokerto. Skripsi. Institute Agama Islam Negeri Purwokerto.

Kemendag, R. (2014). Panduan Optimalisasi Media Sosial Untuk Kementerian Perdagangan. (1st ed.). Pusat Humas Kementerian Perdagangan RI.

Mellyanawaty, M., et all. (2018). Sosialisasi Pengelolaan Limbah Dapur Serta Program 3R Bagi Pemilik Rumah Makan dan Jasa Boga di Wilayah Kota Tasikmalaya. Jurnal Abdimas UMTAS, 1(1), h.53-62.

PP. Pengelolaan Sampah Rumah Tangga dan Sampah Sejenis Sampah Rumah Tangga, Pub. L. No. 81, 1 (2012).

Subekti, S. (2010). Pengelolaan Sampah Rumah Tangga 3R Berbasis Masyarakat. In Prosiding Seminar Nasional Sains dan Teknologi 2010. h. I.24-I.30.

Tamyuiz, M., Hamidah, L. N., Widiyanti, A., \& Rahmayanti, A. (2018). Pelatihan Pengelolaan Sampah Rumah Tangga Di Desa Kedungsumur, Kecamatan Krembung, Kabupatan Sidoarjo. Journal of Scence and Social Development, 1(1), h.16-23.

Yanuar, D. A. (2018). Sosialisasi Tentang Pengelolaan Sampah dan Program Citarum Harum. Retrieved from http://www.jelegong-kutawaringin.desa.id/first 